\begin{tabular}{|c|c|c|}
\hline & International Journal of Current Research in \\
Biosciences and Plant Biology & Volume 5 - Number 6 (June-2018) ・ ISSN: 2349-8080 (Online) \\
\hline EXCELLENT \\
PUBLISHERS
\end{tabular}

\title{
The Role of 2, 2-Dichlorovinyl Dimethyl Phosphate and the Dynamics of Heavy Metals Absorption/Translocation in Plants: Emphasis on Sorrel and Spinach
}

\author{
H. Garba, D. Y. Shinggu, I. B. Bwatanglang* and T. S. Magili
}

Department of Pure and Applied Chemistry, Faculty of Science, Adamawa State University Mubi, Nigeria

*Corresponding author.

\section{Article Info \\ Date of Acceptance: \\ 28 April 2018 \\ Date of Publication: \\ 06 June 2018}

\section{Keywords}

Dichlorvos

Heavy metals

Pesticides

Sorrel

Spinach

\section{ABSTRACT}

Plant protection products in addition to their specific roles were observed to exhibit a characteristic impact towards increasing metal bioavailability within soil and streaming rate in plants. In this study, the role of the pesticides, 2, 2-dichlorovinyl dimethyl (diclorvos) in influencing heavy metal uptake and bioavailability was evaluated by comparing the concentration in the roots, stem and leaves of spinach (Spinacia oleracea) and sorrel (Rumex acetosa) cultivated with and without the pesticides. Atomic absorption spectrometry was used to determine the concentration of the heavy elements in the plant. The fraction of the heavy metals $(\mathrm{Cd}, \mathrm{Pb}$ and $\mathrm{Zn})$ taken up by both the spinach and sorrel plant treated with the pesticides compared to the untreated were observed to follow the trend $\mathrm{Pb}>\mathrm{Cd}>\mathrm{Zn}$ respectively. The correlation between the pesticides treated plant and the untreated plants in metal concentration was visible for the aboveground part of the plants. The measured concentration of $\mathrm{Cd}, \mathrm{Pb}$ and $\mathrm{Zn}$ when compared among the various organs shows an elevated amount in the leaves, particularly in $\mathrm{Pb}$ concentrations. From the results, the dichlorvos was observed to facilitate significant metal uptake in the spinach compared to the sorrel plants irrespective of the plants organs under investigation. From the results, it could be said that the significant $(p<0.05)$ metal concentrations in the treated spinach compared to the treated sorrel plant could be attributed to some severe physiological stress induced by the metal-dichlorvos complex leading to morphological alterations, probably though the dissociation of the diffusive boundary layer or from dust-laden particulate complexing with the residual pesticides on the leaves and trans locating through the stomata. 


\section{Introduction}

Heavy metals translocation are observed to initiates both transient and pronounced disturbances in the chemistry and physiology of plants in vitro and in vivo with its attended ramifications to living organism via the food chain. Fundamentally participating in vitro in inducing the formation of reactive oxygen species (ROS) or reactive nitrogen species (RNS) in plants, inactivating enzymatic processes and inciting the compartmentalization of heavy metals for essential element (Degryse et al., 2012; Srivastava et al., 2018). The in vivo effects were also observed to introduce spatial disorientation in cell-membrane integrity and architecture (Douchiche et al., 2010).

The dynamics of metal ions transport into plants among other pathways rest on the high negative potential of the plasma membrane and further, to the increased cation-exchange capacity of the cell wall (Raskin et al., 1997). Due to the negativecharge potentials on the soil surface, soluble metals ions are readily attracted and deposited at the surface of the soil particles. The cations deposited at the surface of the soil particles, based on some diffusion mechanism (passive diffusion or electrochemical gradient potential) are equally displaced by charged metabolite secreted on the plant roots leaving behind available metal-cations for uptake and translocation through the roots (Fergusson, 1990; Srivastava et al., 2017).

Studies revealed a direct relationship between the deterioration in soil fertility and the decline in plant growth following the excessive application of plant protection products such as pesticides (GloverAmengor and Tetteh, 2008; Kaur et al., 2017; Racke et al., 1997; Sharma et al., 2016). Study that involved the role played by pesticides or fertilizers as metal-chelating vehicle in the translocation of metals in plants are seldom investigated. Chiroma et al. (2007) investigated the impact of pesticides on metal accumulation in two species of spinach plant. The study revealed higher uptake in the spinach treated with the pesticides, with the maroon species showing significant accumulation compared to the green spinach species. The study is however, limited to the two species of spinach with little emphasis giving to the chemistry and physiology of the plant as related to the uptake and translocation of the metal-pesticides. Is a known fact that, factors such as soil composition/or chemistry were observed to influence soil-metal bioavailability and exhibit the chelating properties of the pesticides with metals. Furthermore, based on the differences in plant physiology, this factors invariably influences the uptake and translocation of substances in plants. Since the uptake of metals by plants varies according to the metal-chelating properties with pesticides, the soil $\mathrm{pH}$ and differences in plant physiology, further study is therefore encourage to investigate the influence of pesticides and its dynamic on metal accumulation and translocation among deferent plants types.

The dynamic role of pesticides in the uptake and translocation of metal in plants are observed to be influenced by the complexation chemistry between the pesticides and the metal ions, the soil types and the plant-species or types (Kaur et al., 2017). These complexation reaction are reported to directly facilitate the mobility and persistency of pesticidesmetal complex in soil and which according to other studies could influence the effective uptake by plant (Hwang et al., 2017).

The 2, 2-dichlorovinyl dimethyl phosphate (dichlorvos) is an organophosphate pesticides with phosphorus being the core nuclei. Diclorvos among most pesticides are biodegradable and are considered relatively secure (Chambers et al., 2010). But the degradation potential were observed to be directly dependent on the microbial composition, the $\mathrm{pH}$, temperature and their structural arrangement. The chemistry involved in the chelation of the organophosphate pesticides with metal ion in the soil environment is facilitated between the metal ions acting as an electrophile and the coordinating phospheryl oxygen atom. This interaction enhances the electrophilicity of the phosphorus thus,making it more susceptible to attack by hydroxyl groups or water (Chambers et al., 2010). 
Therefore, the foundation for this study is to have a look into the influence of pesticides in facilitating the uptake and translocation of heavy metals $(\mathrm{Cd}$, $\mathrm{Pb}$ and $\mathrm{Zn}$ ). Since the physiology and morphology of plants varies with species and types, it's therefore postulated that the toxicity response mechanism will also differs and their specific metal compartmentalization will have a different physiochemistry. Therefore, this present study is narrowed towards comparing the influence of the pesticides (2, 2-dichlorovinyl dimethyl phosphate) in heavy metals bioaccumulation among two widely edible vegetable plant in Mubi, Adamawa state of Nigeria (Spinach and Sorrel).

\section{Materials and methods}

\section{Sample collection and treatment}

A representative standard plot of garden (about 10 $\times 10 \mathrm{~m}$ ) were prepared and used in this study. We employed the same procedure described by Chiroma et al. (2007). The garden was evenly demarcated into four beds designated as $\mathrm{B}_{1}, \mathrm{~B}_{2}, \mathrm{~B}_{3}$, and $\mathrm{B}_{4}$ beds respectively. The plot in $\mathrm{B}_{1}$ and $\mathrm{B}_{2}$ were planted with spinach (Spinacia oleracea), while $\mathrm{B}_{3}$ and $\mathrm{B}_{4}$ were planted with sorrel (Rumex acetosa). The beds were maintained and irrigated using clean tap water under environmental condition. Three weeks after planting, $\mathrm{B}_{2}, \mathrm{~B}_{4}$ beds (treated plants) were sprayed with 2, 2-dichlorovinyl dimethyl phosphate, while $\mathrm{B}_{1}, \mathrm{~B}_{3}$ beds were used as the control beds (untreated plants). The treatment of the plants in $\mathrm{B}_{2}, \mathrm{~B}_{4}$ beds with the pesticide was repeated weekly for 3 months. After maturity, the plants in the respective beds were harvested, washed properly and separated into three sample parts, the roots, stem and leaves respectively. The parts were respectively air-dried and made into powder follow by oven drying (VECSTAR 2010 UK) to constant weight at $60^{\circ} \mathrm{C}$. After the drying, approximately10 $\mathrm{g}$ of the respective powdered samples were weighed into a crucible and made into ash at $450^{\circ} \mathrm{C}$. About $2 \mathrm{~g}$ of the cooled ashed samples were then digested using 3:1 ratio of $\mathrm{HCl}$ : $\mathrm{HNO}_{3}$ and diluted to $100 \mathrm{ml}$ with distilled water. Standard solution of the metals were prepared and the concentrations of the following metals $\mathrm{Cd}, \mathrm{Pb}$, and $\mathrm{Zn}$ in the digested roots, stem and leaves samples of both the treated and untreated spinach and sorrel were then investigated using atomic absorption spectroscopy (VGP 210, Buck Scientific)

\section{Data analysis}

The obtained results were presented as Mean \pm Standard Deviation (SD) and analysed using oneway ANOVA on Graph pad prism (version 6.0) software. The levels of significance was set at $p<0.05$.

\section{Results}

The influence of dichlorvos on heavy metals accumulation and translocations in the roots, stem and the leaves of both spinach and sorrel plants are presented in Fig. 1-5. As shown in Fig.1a, a significant $(p<0.05)$ increase in $\mathrm{Cd}$ and $\mathrm{Pb}$ concentrations were found in the roots of the spinach $(10.40 \pm 2.08$ and $17.50 \pm 3.70$ when compared to their respective control $(7.60+2.34$ and $11.00 \pm 2.78)$ However, an insignificant $(p>0.05)$ increase in the levels of $\mathrm{Zn}(2.40 \pm 0.44)$ were observed in the same organ compared to the untreated (2.30 \pm 0.19$)$. The total metals concentration in the roots followed the ranking $\mathrm{Pb}>\mathrm{Cd}>\mathrm{Zn}$ respectively.

With the exception of $\mathrm{Zn}$ which shows an insignificant $(p>0.05)$ increase, a significant $(p<0.05)$ increase in the level of $\mathrm{Cd}$ and $\mathrm{Pb}$ concentrations were observed in the stem. Higher activity was also observed in the level of $\mathrm{Pb}$ $(21.00 \pm 0.05)$ and $\mathrm{Cd}(13.80 \pm 0.20)$ in the treated leaves when compared to their respective untreated beds (12.50 \pm 0.51 and $10.40 \pm 0.53)$. The $\mathrm{Zn}$ levels in the treated plants $(2.45 \pm 1.12)$ when compared to the untreated $(2.45 \pm 0.55)$ showed an insignificant $(p>0.05)$ activity. Fig. 2 shows the activity of the metals in the leaves (Fig. 2a) and the comparison of their respective effects in the roots, stem and leaves (Fig. 2b). From the results in Fig. 2a, a significant 
$(p<0.05)$ increase in $\mathrm{Cd}(15.40 \pm 0.34)$ and $\mathrm{Pb}$ $(26.50 \pm 0.65)$ concentrations were recorded in the leaves of the spinach treated with the pesticides compared to their respective controls $(13.40 \pm 0.79$ and $17.50 \pm 0.35)$. However, only slight insignificant $(p>0.05)$ increase were observed in the $\mathrm{Zn}$ ion concentration (3.35 \pm 0.41$)$ compared to the control

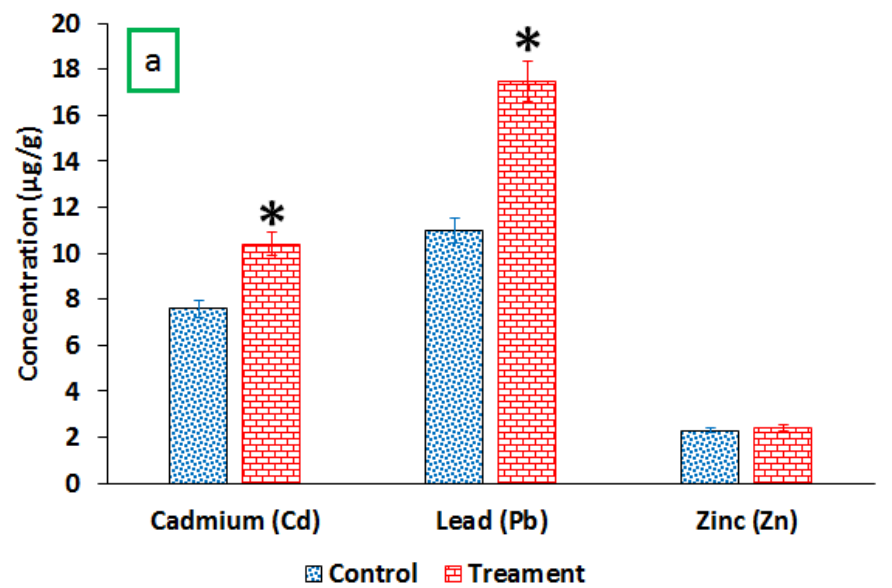

$2.75 \pm 0.21)$. Furthermore, the accumulation and translocation of the metals, $\mathrm{Cd}, \mathrm{Pb}$ and $\mathrm{Zn}$ were compared with respect to their levels in the roots, stem and leaves. From the results, the translocation of the metals under investigations followed the ranking, leaves>stems>roots. The results are presented in Fig. 2b.

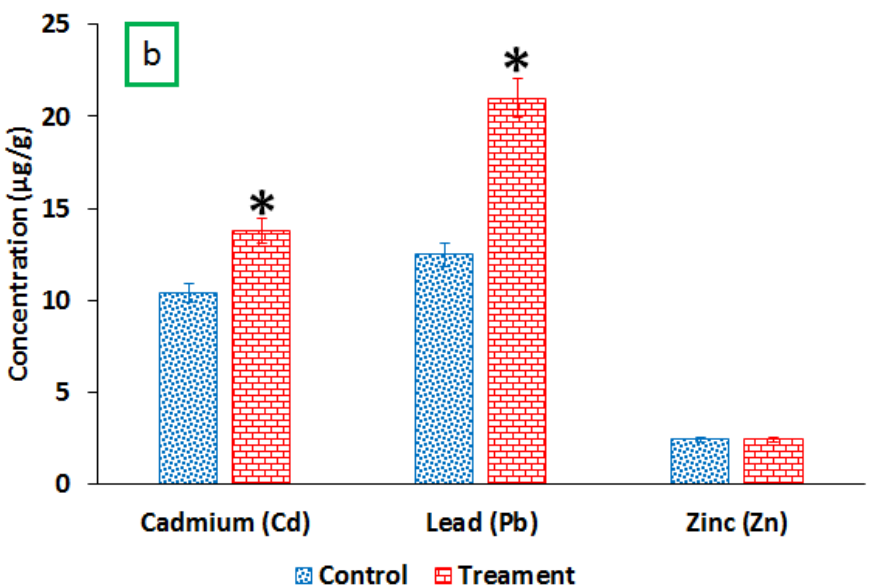

Fig. 1: Concentration of heavy metals $(\mathrm{Cd}, \mathrm{Pb}$ and $\mathrm{Zn})$ in (a) roots (b) stem of spinach cultivated with and without pesticides treatment. Results are presented as Mean \pm SD of triplicate analysis. From the figure, * correspond to significant $(p<0.05)$ value.
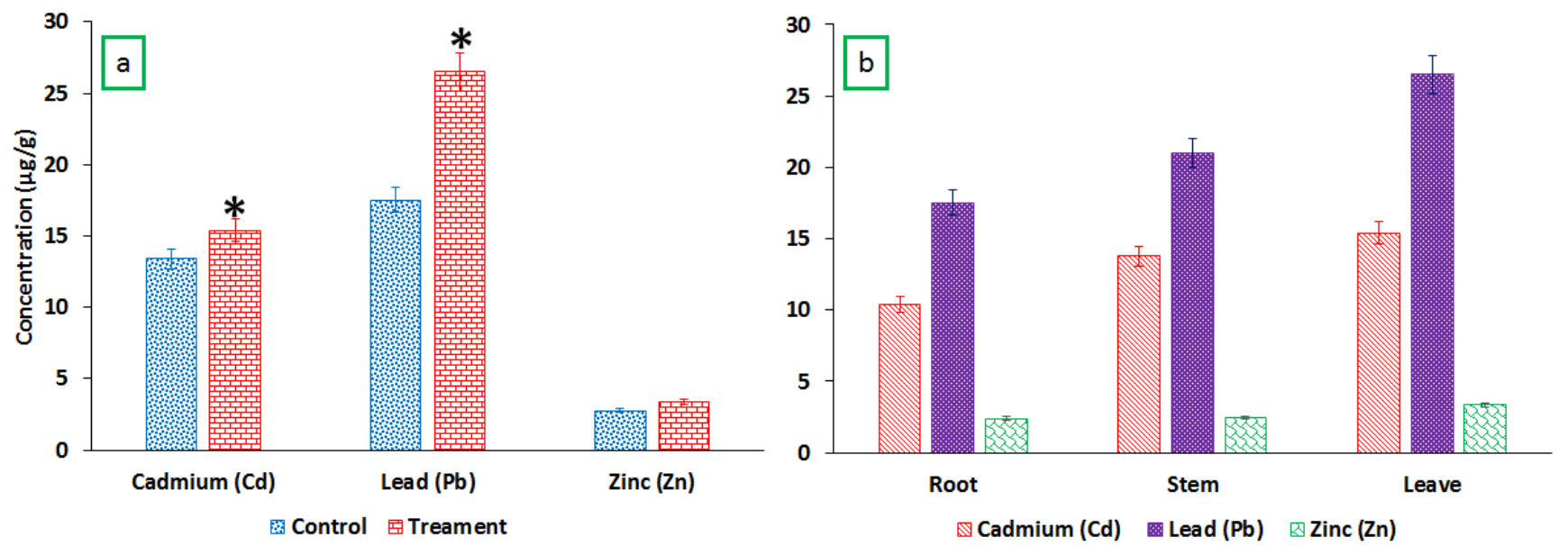

Fig. 2: Concentration of heavy metals $(\mathrm{Cd}, \mathrm{Pb}$ and $\mathrm{Zn})$ in (a) the leaves of spinach cultivated with and without pesticides treatment. And (b) showing comparison $\mathrm{Cd}, \mathrm{Pb}$ and $\mathrm{Zn}$ activities in the roots, stem and leaves of the spinach treated with the pesticides. Results are presented as Mean \pm SD of triplicate analysis. From the figure, $*$ correspond to significant $(p<0.05)$ value.

Contrary to what is observed in the activity levels of the metals in the spinach treated with the dichlorvos, the sorrel plants treated with the same pesticides showed an insignificant $(p>0.05)$ metal accumulation in the roots (Fig.3a) and stems (Fig.3b) compared to their respective untreated plants. The roots accumulated about $9.80 \pm 1.24,9.80 \pm 0.28$ and $2.40 \pm 0.20$ of $\mathrm{Cd}, \mathrm{Pb}$ and $\mathrm{Zn}$ respectively. The trend followed the pattern $\mathrm{Cd}>\mathrm{Pb}>\mathrm{Zn}$. While in the stem, $9.90 \pm 1.28$ of $\mathrm{Cd}$ were recorded, with about $9.6 \pm 3.25$ of $\mathrm{Pb}$ and $2.40 \pm 0.22$ of $\mathrm{Zn}$ concentration observed in the same organ. 

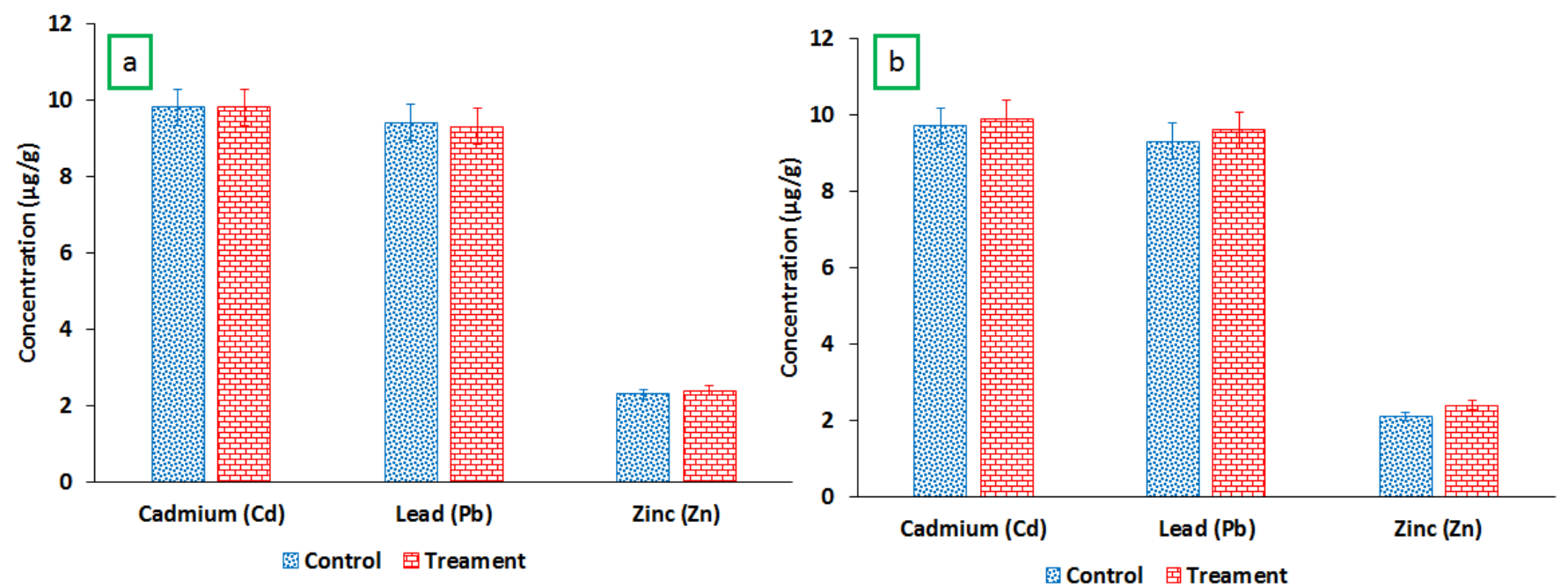

Fig. 3: Concentration of heavy metals $(\mathrm{Cd}, \mathrm{Pb}$ and $\mathrm{Zn})$ in the roots (a) and stem (b) of sorrel cultivated with and without pesticides treatment. Results are presented as Mean \pm SD of triplicate analysis. From the figure, $*$ correspond to significant $(p<0.05)$ value.

However, a different trend was observed in the results presented in Fig. 4a with respect to sorrel treated with the pesticides. With the exception of the leaves which was observed to accumulate significant $(p<0.05)$ amount of $\mathrm{Pb}(18.50 \pm 3.15)$

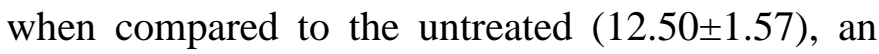
insignificant $(p>0.05)$ increase in $\mathrm{Cd}(11.00 \pm 0.24)$ and $\mathrm{Zn}(2.45 \pm 0.20)$ levels were observed in the same organ compared to their respective untreated $(10.40 \pm 1.28,2.15 \pm 0.53)$ groups.
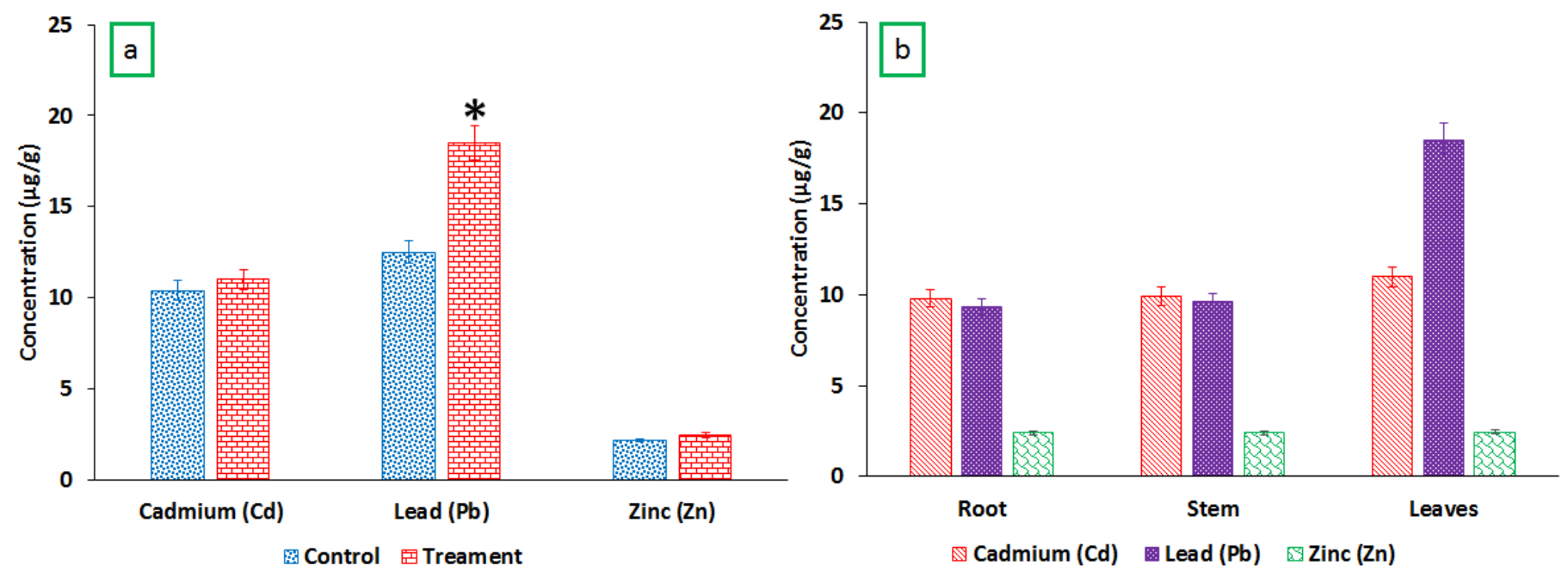

Fig. 4: Concentration of heavy metals $(\mathrm{Cd}, \mathrm{Pb}$ and $\mathrm{Zn})$ in (a) the leaves of sorrel cultivated with and without pesticides treatment. And (b) showing comparison $\mathrm{Cd}, \mathrm{Pb}$ and $\mathrm{Zn}$ activities in the roots, stem and leaves of the spinach treated with the pesticides. Results are presented as Mean \pm SD of triplicate analysis. From the figure, ${ }^{*}$ correspond to significant $(p<0.05)$ value.

From the results shown in Fig.5, the 2, 2dichlorovínyl dimethyl phosphate was observed to facilitate significant metal uptake in the spinach compared to the sorrel plants. In particular, significantly higher accumulation was observed in the leaves and roots compared to the stem. In all the plants organ under investigation, the concentration of $\mathrm{Cd}, \mathrm{Pb}$ and $\mathrm{Zn}$ was observed to be greater in the spinach than in sorrel plants. 

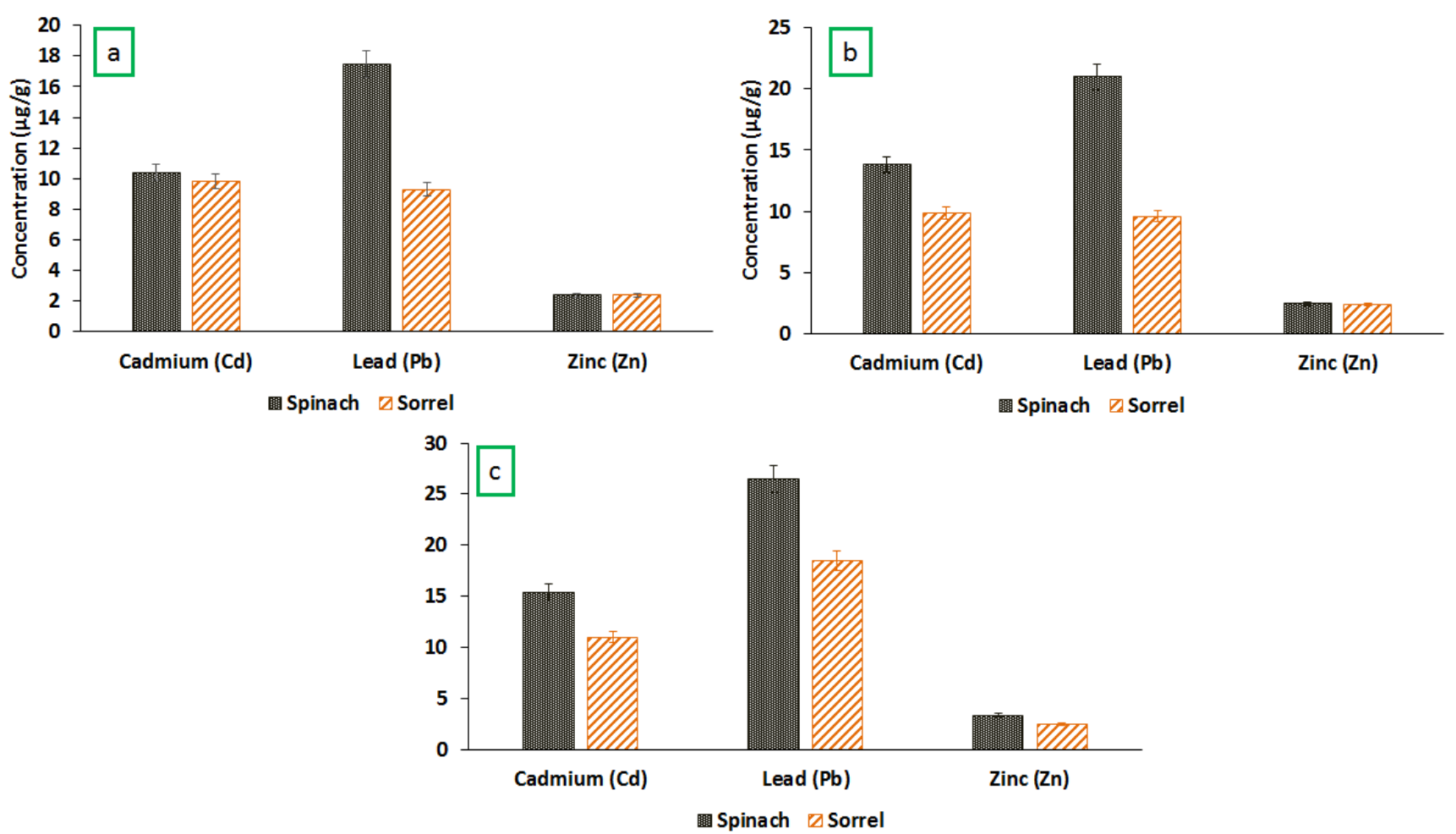

Fig. 5: Variation in mean metals $(\mathrm{Cd}, \mathrm{Pb}$ and $\mathrm{Zn})$ concentration in the spinach treated with the pesticides compared with that of sorrel treated with the pesticides.

\section{Discussion}

It has being established that plants following some physiochemical processes formed chelates with metals presents in the soil and through this processes, facilitate the absorption of these metals through the plants roots (Kumar et al., 2015; Skiba et al., 2017). Is therefore hypothesis that, pesticides residue in the soil, following the same processes could act as a potential competitors to chelate metal ions in the soil, (Kumar et al., 2015). In this study, the pesticides "dichlorvos" was used in order to investigate the impact of pesticides in simulating the uptake and translocation of metal ions in plants. The dichlorvos is an organophosphate pesticides and due to the available "O" donor site (the phospheryl oxygen) could chelates readily with metals ions like $\mathrm{Cd}, \mathrm{Pb}, \mathrm{Zn}$ and $\mathrm{Fe}$ (Gupta and Milatovic, 2012). This properties increase the chelating potential of organophosphate pesticides with essential and heavy metal ions of soil/water medium (Kaur et al, 2017; Kumar et al., 2015). In addition to this properties, organophosphate pesticides were also discovered to have the ability to creates acidic environment in soil/water medium (Kaur et al., 2017), thus increasing the solubility of sparingly soluble metals ions, since the metal-ions bioavailability in soils were observed to decrease above pH 5.5-6 (Seuntjens et al., 2004; Van Ginneken et al., 2007).

In this study, the accumulation of the metal ions in the roots, stem and leaves of spinach plants followed the ranking $\mathrm{Pb}>\mathrm{Cd}>\mathrm{Zn}$. Though, higher concentration of lead content were equally recorded in the roots and stem, the results further shows significantly higher content in the leaves. Due to its low solubility, the amount of $\mathrm{Pb}$ taken up by plants roots are found to be in the form of extracellular precipitates (as phosphates, carbonate and sulphates (Blaylock and Huang, 2000). In its precipitating form, $\mathrm{Pb}$ was observed to preferential bind to the carboxylic moiety of the uronic acids secreted on the root surface of plant (Morel et al., 1986; Sharma and Dubey, 2005). Thereby making the roots the first point of contact and a barrier for further 
translocation of the $\mathrm{Pb}$ upstream. The slight increase in $\mathrm{Pb}$ concentrations recorded in the roots and stem compared to the significant amount recorded in the leaves suggest the possibility of a small fraction of the absorbed $\mathrm{Pb}$ translocated upwards through the roots. Studies further shows that a small portion of plant exposed to $\mathrm{Pb}$ could find their way through the roots to the stem and leaves and probably to the seeds (Peralta-Videa et al., 2009). But this cannot be fully substantiated regarding the significant $\mathrm{Pb}$ accumulation in the leaves of spinach compared to the control observed in this study.

Other related studies reported poor correlation between the concentration of $\mathrm{Pb}$ in leafy vegetable plants and its bioavailability in contaminated soil. According to the study, the poor correlation persisted despite putting into the equation other factors such as $\mathrm{pH}$ and organic matter content into the analysis (Udovic and McBride, 2012; Witzling et al., 2010); suggesting atmospheric deposition as the source of the $\mathrm{Pb}$ than from the soil. The translocation of $\mathrm{Pb}$ from the roots upstream is rare, thus, the translocation of $\mathrm{Pb}$ aboveground tissues could be associated with dust-laden particulate emanated from anthropogenic activities, impacting on the leaves and translocating through the stomata (Brokbartold and Marschner, 2011; McBride et al., 2014; Mleczek et al., 2011).

Despite the significant uptake in $\mathrm{Cd}$ and $\mathrm{Pb}$ concentrations in the respective organs of the spinach plants, less activity were observed in regards to $\mathrm{Zn}$ ion concentrations in all the organs compared to the control. It was reported that the uptake route for $\mathrm{Cd}$ through the roots followed the same route to most divalent micronutrient such as $\mathrm{Zn}$ ion. Cadmium and $\mathrm{Zn}$ being a chemical analogue of each other could compete in chelation and interaction with the plants. Thus, if the concentration of $\mathrm{Cd}$ is higher in the medium, the possibility of effective uptake of $\mathrm{Zn}$ ion could be hampered by the competing Cd ion (Degryse et al., 2012).

Further similar trend were also observed in the sorrel plants treated with the pesticides when compared to the control. However, the effects were found not to be significant. From the results, it was also observed that the uptake and translocation of the metals ion appeared to be more in the spinach plants compared to the sorrel irrespective of the plants organs under investigation. In a separate study, based on the correlation coefficient investigated, it was found that the concentration of heavy metals in the soil and the amount taken up by sorrel were generally low (Gawęda, 2009). The deduction made from the investigation were related to the barrier limiting properties of the roots towards obstructing the absorption of metals aboveground parts (Salim et al., 1992). The results from this study shows spinach experiencing higher metals induced stress than sorrel based on the measured concentrations of the accumulated metals in the roots, stem and leaves. According to other findings, the rate of metal uptake by roots rely solely in her ability to tolerate metal-induced oxidative stress (Antosiewicz, 1993; Wierzbicka and Antosiewicz, 1993). Thus, the lower metal content in the sorrel could be connected to her barrier limiting properties (Gawęda, 2009). One possible explanation owed to these differences could be due to the variation in their morphology and physiological chemistry. The sorrel in this context, as observed in the study might have applied exclusion mechanism by inhibiting the absorption of this heavy metals by the roots (Gawęda, 2009; Salim et al., 1992; Wierzbicka and Antosiewicz, 1993).

From the results in this study, it could be said that spinach might have expressed some physiological stress leading to morphological changes compared to the sorrel plant. In a study documented by Schaider et al. (2006), physiological stress was observed to increase significant absorption of metal-chelate complexes. Which according to other findings facilitated through the dissociation with diffusive boundary layer (Panfili et al., 2009).

Plant possess the abilities to renders toxic metabolites benign, thus increasing their chances of survival and tolerance to physiological stress. Their response mechanism to metals induced stress could 
be linked to the activities of mycorrhiza to inhibit the metals absorption by plants (Amir et al, 2014). Similarly, the root cells due to the formation of complexes with amino acids or available organic substances were observed to deactivate or reduce the toxic potentials of heavy metals (Rascio and Navari-Izzo, 2011), thus checkmating the mobility and translocation of heavy metals upstream and the possibility of the metals causing injury (Hassan, 2011; Rascio and Navari-Izzo, 2011; Sharma et al., 2016). In a situation were small fraction of the metals penetrates the roots cell membranes, research shows that the metals will interacts with the carboxylate moiety of pectin and increase the thickness of the cell wall leading to plant high tolerance and resistance to metal toxicity (Krzesłowska, 2011).

In contrast to $\mathrm{Cd}$ and $\mathrm{Pb}$, the presence of metalpesticides complexes formed following the treatment of the spinach and sorrel with the dichlorvos exerted little effect on the uptake of $\mathrm{Zn}$. Studies shows that the $\mathrm{Zn}$ uptake by plans depends on the metal concentration in the soil (Skiba et al., 2017) and its competitiveness in forming complexes with chelating agents (Yashim et al, 2014). Though, the concentrations of the heavy metals recorded (in both the spinach and sorrel treated with the pesticides) were respectively within the tolerable levels of $30 \mu \mathrm{g} / \mathrm{g}, 300 \mu \mathrm{g} / \mathrm{g}$ for Cd and $\mathrm{Pb}$ (Chiroma et al., 2007). The findings however, provides more insight into the underlining mechanism leading to increase metal uptake and translocation exhibited by the application of plant protection products such as 2, 2-dichlorovinyl dimethyl phosphate. The results of the study are however reported taking into cognizance the limited concentration of the respective heavy metals in the soil in relation to their uptake by the cultivated crops.

\section{Conclusion}

With the exception of $\mathrm{Zn}$ ion which shows little response to pesticides application, $\mathrm{Cd}$ and $\mathrm{Pb}$ concentration were observed to be influence by the pesticides, with significantly $(p<0.05)$ higher activities recorded in leads levels. The 2, 2dichlorovinyl dimethyl phosphate was observed to facilitate significant metal uptake in the spinach compared to the sorrel plants. In particular, significantly $(p<0.05)$ higher accumulation was observed in the leaves and roots compared to the stem. In all the plants organ under investigation, the concentration of $\mathrm{Cd}, \mathrm{Pb}$ and $\mathrm{Zn}$ was observed to be greater in the spinach than in sorrel plants. The variations could be due to the differences in the plant morphology and physiological sensitivity to this metals-pesticide complex. Therefore, it suffice to say that further in vitro and in vivo study into the plant structure following the application of the pesticides should be combined with the physiological response mechanism of the plants as it affect metal ion uptake and transport. The alteration in the roots, stem and leaves following the uptake of the metal-pesticides complex may provide us with additional understanding towards the differences in plants system and their individual uptake and translocation rates.

\section{Conflict of interest statement}

Authors declare that they have no conflict of interest.

\section{Acknowledgement}

Authors acknowledge the Department of Pure and Applied Chemistry, Adamawa State University, Mubi for providing the facilities. The authors would also like to thank the Faculty of Science and Agriculture (Adamawa State University) for their unflagging support.

\section{References}

Amir, H., Jourand, P., Cavaloc, Y., Ducousso, M., 2014. Role of Mycorrhizal Fungi in the Alleviation of Heavy Metal Toxicity in Plants. In: Solaiman Z, Abbott L, Varma A (Edition) Mycorrhizal Fungi: Use in Sustainable Agriculture and Land Restoration. Soil Biology, 41. Springer, Berlin, Heidelberg.

Antosiewicz, D.M., 1993. Mineral status of 
dicotyledonous crop plants in relation to their constitutional tolerance to lead. Environ. Exp. Bot. 33, 575-589.

Blaylock, M.J., Huang, J.W., 2000. Phytoextraction of metals. Phytoremediation of toxic metals: Using plants to clean up the environment. (Eds: I. Raskin and B.D. Ensley). Wiley, New York: 53-70.

Brokbartold, M., Marschner, B., 2011. Bodenbelastungen durch bleihaltige Korrosionsschutzfarbe: eine Pb-Quelle mit außergewöhnlicher Mobilitätscharakteristik. Bodenschutz (04/2011). Erich Schmidt Verlag, Berlin.

Chambers, J.E., Meek,E.C., Chambers, H.W., 2010. The metabolism of organophosphorus insecticides. In: Hayes' Handbook of Pesticide Toxicology (R. Krieger, Ed.) $3^{\text {rd }}$ Edn.). Academic Press, San Diego. pp.1399-1407.

Degryse, F., Shahbazi, A., Verheyen, L., Smolders, E., 2012. Diffusion limitations in root uptake of cadmium and zinc, but not nickel, and resulting bias in the Michaelis constant. Plant Physiol. 160, 1097-1109.

Douchiche, O., Driouich, A., Morvan, C., 2010. Spatial regulation of cell-wall structure in response to heavy metal stress: cadmiuminduced alteration of the methyl-esterification pattern of homogalacturonans. Ann. Bot. $105,481-491$.

Fergusson, J.E., 1990. Heavy elements: chemistry, environmental impact and health effects. Pergamon. $1^{\text {st }}$ Edn. Pergamon Press, Oxford; New York. pp.211-212.

Gawęda, M., 2009. Heavy metal content in common sorrel plants (Rumex acetosa L.) obtained from natural sites in Małopolska Province. Pol. J. Environ. Stud. 18, 213-218.

Glover-Amengor, M., Tetteh, F.M., 2008. Effect of pesticide application rate on yield of vegetables and soil microbial communities. West Afr. J. Appl. Ecol.12,1-12

Gupta, R.C., Milatovic, D., 2012. Toxicity of organophosphates and carbamates. In: Mammalian Toxicology of Insecticides: $\left(1^{\text {st }}\right.$ ed $)$ Royal Society of Chemistry. Cambridge, UK. pp.184-220.
Hassan, Z., Mark, G.A., 2011. Opportunities and feasibilities for biotechnological improvement of $\mathrm{Zn}, \mathrm{Cd}$ or Ni tolerance and accumulation in plants. Environ. Exp.Bot. 72, 53-63.

Hwang, J.I., Lee, S.E., Kim, J.E., 2017. Comparison of theoretical and experimental values for plant uptake of pesticide from soil. PloS One. 12, e0172254.

Kaur, S., Kumar, V., Chawla, M., Cavallo, L., Poater,A., Upadhyay, N., 2017. Pesticides curbing soil fertility: effect of complexation of free metal ions. Fron. Chem.5,43-49.

Krzesłowska, M., (2011). The cell wall in plant cell response to trace metals: polysaccharide remodeling and its role in defense strategy. Acta Physiol. Planta.33, 35-51.

Kumar, A., Bahadur, I., Maurya, B., Raghuwanshi, R., Meena, V.S., Singh, D.K., Dixit, J., 2015. Does a plant growth-promoting rhizobacteria enhance agricultural sustainability. J. Pure Appl. Microbiol. 9, 715-724.

McBride, M., Shayler, H.A., Spliethoff, H.M., Mitchell, R.G., Marquez-Bravo, L.G., Ferenz, G.S., Bachman, S., 2014. Concentrations of lead, cadmium and barium in urban gardengrown vegetables: the impact of soil variables. Environ. Poll. 194, 254-261.

Mleczek, M., Kozłowska, M., Kaczmarek, Z., Magdziak, Z., Goliński, P., 2011. Cadmium and lead uptake by Salix viminalis under modified $\mathrm{Ca} / \mathrm{Mg}$ ratio. Ecotox. 20, 158-165.

Morel, J.L., Mench, M., Guckert, A., 1986. Measurement of $\mathrm{Pb} \mathrm{2+,} \mathrm{Cu} \mathrm{2+}$ and $\mathrm{Cd} \mathrm{2+}$ binding with mucilage exudates from maize (Zea mays L.) roots. Biol. Fert. Soils. 2, 29-34.

Chiroma, M.T., Bala, I., Haruna, K., 2007. The impact of pesticide application on heavy metal $(\mathrm{Cd}, \mathrm{Pb}$ and $\mathrm{Cu})$ levels in Spinach. Leon. Electr. J. Pract. Technol. 6, 117-122.

Panfili, F., Schneider, A., Vives, A., Perrot, F., Hubert, P., Pellerin, S., 2009. Cadmium uptake by durum wheat in presence of citrate. Plant Soil. 316, 299-309.

Peralta-Videa, J.R., Lopez, M.L., Narayan, M., Saupe, G., Gardea-Torresdey, J., 2009. The biochemistry of environmental heavy metal 
uptake by plants: implications for the food chain. Int. J. Biochem. Cell Biol. 8, 1665-1677.

Racke, K.D., Skidmore, M.W., Hamilton, D.J., Unsworth, J.B., Miyamoto, J., Cohen, S.Z., 1997. Pesticides report 38. Pesticide fate in tropical soils (technical report). Pure Appl. Chem. 69, 1349-1372.

Rascio, N., Navari-Izzo, F., 2011. Heavy metal hyperaccumulating plants: how and why do they do it? And what makes them so interesting? Plant Sci. 180, 169-181.

Raskin, I., Smith, RD., Salt, D.E., 1997. Phytoremediation of metals: using plants to remove pollutants from the environment. Curr. Opin. Biotechnol. 8, 221-226.

Salim, R., Hagemeyer, J., Al-Subu, M.M., Atallah, A., Chenavier, L., 1992. Effects, on growth and uptake distribution, of root and foliar treatments of marrow plants with cadmium and lead solutions. J. Environ. Sci. Health Part A. 27, 2173-2190.

Schaider, L.A., Parker, D.R., Sedlak, D.L., 2006. Uptake of EDTA-complexed $\mathrm{Pb}, \mathrm{Cd}$ and $\mathrm{Fe}$ by solution-and sand-cultured Brassica juncea. Plant Soil. 286, 377-391.

Seuntjens, P., Nowack, B., Schulin, R., 2004. Rootzone modeling of heavy metal uptake and leaching in the presence of organic ligands. Plant Soil. 265, 61-73.

Sharma, A., Gangola, S., Khati, P., Kumar, G., Srivastava, A., 2016. Novel pathway of cypermethrin biodegradation in a Bacillus sp. strain SG2 isolated from cypermethrincontaminated agriculture field. 3 Biotech. 6, 45.

Sharma, P., Dubey, R.S., 2005. Lead toxicity in plants. Braz.J. Plant. Physiol. 17, 35-52.

Skiba, E., Kobyłecka, J., Wolf, W. M., 2017. Influence of 2, 4-D and MCPA herbicides on uptake and translocation of heavy metals in wheat (Triticum aestivum L.). Env. Poll. 220, 882-890.

Srivastava, R.K., Rajpoot, R., Pandey, P., Rani, A., Dubey, R.S., 2018. Cadmium alters mitochondrial membrane potential, inhibits electron transport chain activity and induces callose deposition in rice seedlings. J. Plant Growth Regul. 37, 335-344.

Srivastava, V., Sarkar, A., Singh, S., Singh, P., de Araujo, A.S., Singh, R.P., 2017. Agroecological responses of heavy metal pollution with special emphasis on soil health and plant performances. Front. Environ. Sci. 5, 321-342.

Udovic, M., McBride, M.B., 2012. Influence of compost addition on lead and arsenic bioavailability in reclaimed orchard soil assessed using Porcellio scaber bioaccumulation test. J. Hazard. Mater. 205, 144-149.

Van Ginneken, L., Meers E., Guisson, R., Ruttens, A., Elst, K., Tack, F.M.G., Vangronsveld, J., Diels, L., Dejonghe, W., 2007. Phytoremediation for heavy metal-contaminated soils combined with bioenergy production. J. Environ. Eng. Land. Manage.15, 227-236.

Wierzbicka, M., and Antosiewicz, D., 1993. How lead can easily enter the food chain - a study of plant roots. Sci. Tot. Environ.134, 423-429.

Witzling, L., Wander, M., Phillips, E., 2010. Testing and educating on urban soil lead: a case of Chicago community gardens. J. Agric. Food Syst. Comm. Dev. 167e185.

Yashim, Z.I., Israel, O.K., Hannatu, M., 2014. A study of the uptake of heavy metals by plants near metal-scrap dumpsite in Zaria, Nigeria. J. Appl. Chem. Vol. 2014, Article ID 394650, 5 pages.

\section{How to cite this article:}

Garba, H., Shinggu, D.Y., Bwatanglang, I.B., Magili, T.S., 2018. The role of 2, 2-dichlorovinyl dimethyl phosphate and the dynamics of heavy metals absorption/translocation in plants: Emphasis on sorrel and spinach. Int. J. Curr. Res. Biosci. Plant Biol. 5(6), 1-10.

doi: https://doi.org/10.20546/ijcrbp.2018.506.001 